\title{
Spectral characteristics of protons in the Earth's plasmasheet: statistical results from Cluster CIS and RAPID
}

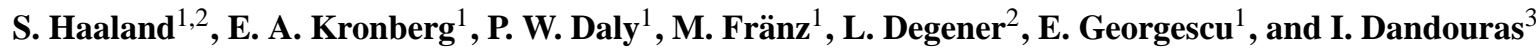 \\ ${ }^{1}$ Max-Planck Institute for Solar Systems, Germany \\ ${ }^{2}$ Department of Physics and Technology, University of Bergen, Norway \\ ${ }^{3}$ Centre d'Etude Spatiale des Rayonnements, France
}

Received: 12 December 2009 - Revised: 12 July 2010 - Accepted: 2 August 2010 - Published: 5 August 2010

\begin{abstract}
We present a study of the spectral characteristics of protons in the Earth's plasma sheet for various geomagnetic disturbance levels. The study is based on about $5400 \mathrm{~h}$ of data combined from the Cluster RAPID and CIS instruments obtained during the tail season (July-October). The overall proton spectral shape is generally that of a $\kappa$ distribution, that is, resembling a Maxwellian at lower energies which smoothly merges into a power-law tail at higher energies. The actual spectral long-term slope depends on various magnetospheric driver parameters, but is on average around 3.5-4. During disturbed conditions, such as geomagnetic storm or substorm periods, a shift in the characteristic energy is observed. For two individual storms, we also found a hardening of the spectra. Unlike the electron spectra, we do not see any significant local time dependence in the spectral slope, but we find higher average ion fluxes in the dusk side. We also do not find any direct response in the energy spectra to changes in the interplanetary magnetic field or solar wind dynamic pressure. This suggests that energization of the ions are mainly due to internal processes in the plasma sheet.
\end{abstract}

Keywords. Magnetospheric physics (Energetic particles, trapped; Magnetotail; Plasma sheet)

\section{Introduction}

Earlier measurements of ions in the Earth's magnetosphere have revealed that the energy distribution often deviates from a pure Maxwellian distribution, and often possesses a high energy tail, which can best be modelled with a power law or $\kappa$ function (Vasyliunas, 1968; Williams et al., 1973; West and

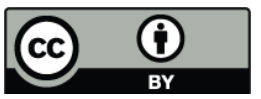

Correspondence to: S. Haaland (stein.haaland@ift.uib.no)
Buck, 1976; Ipavich and Scholer, 1983; Christon et al., 1989, 1991). Such distributions are less stable than Maxwellians and can dramatically enhance the growth of plasma waves under certain conditions (e.g., Thorne and Summers, 1991; Chaston et al., 1997, and references therein). The spectral slope can also provide valuable information about acceleration and diffusion processes.

Christon et al. $(1989,1991)$ used measurements of ions in the energy range $\simeq 30 \mathrm{eV} / \mathrm{q}$ to $2.1 \mathrm{MeV}$ and electrons with energies in the range $\simeq 30 \mathrm{eV} / \mathrm{q}$ to $1.2 \mathrm{MeV}$ from the Earth's nightside plasma sheet, and found that the typical energy spectra could best be described by a $\kappa$ distribution with spectral slopes in the range $\kappa=4-8$.

More recently, Åsnes et al. (2008) used Cluster observations to assess the characteristic energy spectra of electrons with energies above $40 \mathrm{keV}$. They used a power law function, $j \propto e^{-\gamma}$ to fit the spectra and investigated how the $\gamma$ index varied with different disturbance levels and locations. They noted that geomagnetic activity, as represented by the Kp index, had no significant impact on the spectral slope. On the other hand, they observed a local time dependence in the slope, with the electron spectra being harder on the dawn side.

The dawn-dusk asymmetry was also the focus of a study by Sarafopoulos et al. (2001), who used Interball measurements of electrons in the range $27-426 \mathrm{keV}$ and ions in the energy range $27-827 \mathrm{keV}$ as a basis for their study. Using 12 plasma sheet crossings in geocentric distances between $\simeq 13$ $25 R_{\mathrm{E}}$ downtail, they found significant dusk dawn asymmetries. In general the fluxes of ions (electrons) were higher on the dusk (dawn) side. They also found that an increase in geomagnetic activity were associated with particle energization. However, the spectral change were mainly in the form of a shift in characteristic energies, and less so in the spectral shape.

Published by Copernicus Publications on behalf of the European Geosciences Union. 
In this paper we present a survey of proton spectra in the geomagnetic tail for various geomagnetic conditions. The results are based on several years of data from the Cluster mission. In particular, we investigate how the characteristic energy and spectral slope of the proton population respond to geomagnetic activity and changes in the solar wind. We also address the issue of dawn-dusk asymmetry. There are several issues that distinguish our data set from those used in earlier studies. First, Cluster has been operating for several years, and the amount of available data is much larger than for earlier studies. In addition, the availability of nearly continuous solar wind and IMF data provides us with far better opportunities to study the response to external influences such as increased solar wind pressure, and changing IMF directions. Unlike some of the earlier studies based on e.g., ISEE (Christon et al., 1989, 1991) and Interball (Sarafopoulos et al., 2001), we are also better equipped to discriminate between ion species.

This paper is organized as follows: Sect. 2 contains a description of the instrumentation and data set which forms the basis of our study. In Sect. 3 we first present two case studies of spectral changes during geomagnetic storms. In the second part of Sect. 3, we thereafter show long-time characteristic spectra for various disturbance levels and their response to external drivers. Section 4 discusses physical implications and summarizes the results.

\section{Data and instrumentation}

The results presented in this study are mainly based on in-situ measurement from the Cluster quartet of spacecraft. Cluster is an ESA mission comprising four identical spacecraft flying in a tetrahedron like formation. During the period covered by this study, Cluster was in a nearly $90^{\circ}$ inclination elliptical orbit with apogee around $20 R_{\mathrm{E}}$ perigee around $4 R_{\mathrm{E}}$ and a orbital period of approximately $57 \mathrm{~h}$. Within the science community, the four spacecraft are usually referred to as $\mathrm{C} 1$, C2, C3 and C4. Not all instruments work on all spacecraft, and in this paper we have mainly used data from the $\mathrm{C} 1$ and C3 spacecraft, since these give the best data return for our purpose.

In this paper, we focus on spectral properties protons in the energy range $\simeq 700 \mathrm{eV}$ to $1 \mathrm{MeV}$ in the nightside magnetotail and plasma sheet. This region is traversed by Cluster during Northern Hemisphere autumn season, i.e., from late July until October. More information about the Cluster mission and instrumentation can be found in Escoubet et al. (1997).

In addition, solar wind magnetic field and plasma data and geomagnetic disturbance indices are used to check dependencies.

\subsection{Cluster particle measurements}

We utilize ion measurements from two different sensors on board Cluster. Protons with energies above $27 \mathrm{keV}$ are measured by the Research with Adaptive Particle Imaging Detector (RAPID, see Wilken et al., 2001), whereas the lower part of the energy range is covered by the Cluster Ion Spectrometer (CIS, see Rème et al., 2001). For convenience, we provide a brief description of these two detectors.

\subsubsection{Energetic ion fluxes from RAPID}

RAPID consists of three identical mass spectrometers which use a combination of time-of-flight and energy measurements to classify and bin the incident particles. The three sensors cover $180^{\circ}$ in polar angle over the energy range 37$407 \mathrm{keV}$ for electrons, $27 \mathrm{keV}-4 \mathrm{MeV}$ for protons, $30 \mathrm{keV}-$ $3.8 \mathrm{MeV}$ for helium, and approximately $80 \mathrm{keV}-4 \mathrm{MeV}$ for oxygen. Utilizing the spacecraft spin, RAPID was designed to provide the distribution of electrons and ions with complete coverage of the unit sphere in phase space. Due to a degradation of the central heads on all spacecraft during the early phase of the mission, only a reduced part of the full ion 3-D distribution is available during later stages, however. In particular, we are not able to calculate pitch angle distributions based on the RAPID ion sensors.

Since our purpose is to investigate the spectral characteristics of a particular plasma region, we are not dependent on any 3-D abilities, but integrate over all directions to get an omnidirectional flux. Except from a lower count rate, the lack of sensitivity in the central sensor thus does not play any major role as demonstrated by Kronberg et al. (2010).

Although RAPID allows for discrimination of various ion species, we focus on protons only in this study - properties of heavier ions will be addressed separately in a later publication. We divide the RAPID omnidirectional proton fluxes into 6 energy channels and combine them with similar information from the CIS instrument. The energy channel assignment is shown in Table 1. Note that the second channel of RAPID has a fairly narrow energy range. The time resolution of the RAPID data is 1 spin (approximately $4 \mathrm{~s}$ ), but since the count rates are often very low, in particular for the highest energy channels, we decided to use 1 min averages provided by the instrument team for this study.

\subsubsection{Moments and particle measurements from CIS}

The CIS instrument has two sensors. In this paper we use data from the COmposition and DIstribution Function (CODIF) analyzer. CODIF measures 3-D distribution functions of the major ion species in the energy per charge range $0.03-40 \mathrm{keV}$ per charge. Two different data products from CODIF are used; plasma moments and omnidirectional fluxes of protons. 
The onboard calculated plasma moments are used to identify the plasma region and to filter the data. Moments have a native time resolution of 1 spin, but we calculate $1 \mathrm{~min}$ averages and put them on the same time line as the rest of the data set. To calculate plasma $\beta$, i.e., the ratio between particle pressure and magnetic field pressure, we also utilize magnetic field measurements from the Fluxgate Magnetometer (FGM - described in Balogh et al., 2001). Omnidirectional data are based on the full 3-D distribution from the CODIF sensor, and are available at either 8 or $12 \mathrm{~s}$ resolution, depending on the telemetry mode. They are obtained by integrating over all elevation angles and spin sectors of the instrument. As with the rest of the data set, we also construct $1 \mathrm{~min}$ averages of this data set. The CIS instrument has several sensitivity modes, automatically switched in-flight in order to provide optimal sensitivity and resolution for a particular plasma region. Calibration factors are applied accordingly, but the data products differ slightly from one mode to the next. To avoid errors introduced by mode shifting or non-optimal modes, we only use data from the recommended magnetospheric modes (see details in Rème et al., 2001; Dandouras et al., 2006).

\subsubsection{Combining spectral information from CIS and RAPID}

The combined energy spectrum consists of 23 energy channels, 16 from CIS and 7 from RAPID. Table 1 shows the channel numbering and energy ranges of these channels. Note that there is some overlap; the highest energy channel of CIS partly overlaps with the lowest energy range of RAPID.

Although the calibrations of both CIS-CODIF and RAPID have now reached a fairly mature level, combining data from the two instruments can still be a challenge. There are still periods, in particular prior to 2003, when the CIS part of the energy spectrum does not overlap the RAPID part of the spectrum. This typically occurs after one of the instrument gain factors has been adjusted to compensate for degradation in the sensors. For such cases, we have corrected (i.e., multiplied all flux values with a constant factor) the CIS spectra so that the overlapping energy channels agree. This correction has no affect on the spectral shape. A similar procedure was also applied in e.g., Christon et al. (1991).

\subsubsection{Solar wind and magnetospheric disturbance levels}

Disturbances in Earth's magnetosphere, like magnetospheric storms and substorms, are typically associated with dynamic changes in the solar wind, in particular directional changes in the interplanetary magnetic field (IMF). At the Earth's dayside magnetopause, a southward directed IMF can reconnect with the geomagnetic field, and allow energy and momentum to be transferred more directly from the solar wind into the magnetosphere. During periods with enhanced disturbance
Table 1. Assignment of energy channels for the CIS-CODIF and RAPID instruments. The highest energies of CIS-CODIF overlaps with the lower energy range of RAPID.

\begin{tabular}{rrcc}
\hline Ch no. & Energy range & Sensor & Remarks \\
\hline 15 & $738-939 \mathrm{eV}$ & “ & \\
16 & $940-1196 \mathrm{eV}$ & “ & \\
17 & $1197-1523 \mathrm{eV}$ & “ & \\
18 & $1524-1939 \mathrm{eV}$ & “ & \\
19 & $1940-2469 \mathrm{eV}$ & “ & \\
20 & $2470-3144 \mathrm{eV}$ & “ & \\
21 & $3.1-4.0 \mathrm{keV}$ & “ & \\
22 & $4.0-5.1 \mathrm{keV}$ & “ & \\
23 & $5.1-6.5 \mathrm{keV}$ & “ & \\
24 & $6.5-8.2 \mathrm{keV}$ & “ & \\
25 & $8.2-10.5 \mathrm{keV}$ & “ & \\
26 & $10.5-13.4 \mathrm{keV}$ & “ & \\
27 & $13.4-17.0 \mathrm{keV}$ & “ & \\
28 & $17.0-21.7 \mathrm{keV}$ & “ & \\
29 & $21.0-27.6 \mathrm{keV}$ & “ & \\
30 & $27.6-35.2 \mathrm{keV}$ & “ & overlaps RAPID \\
\hline 31 & $27-64 \mathrm{keV}$ & RAPID-IIMS & \\
32 & $75-92 \mathrm{keV}$ & “ & \\
33 & $92-159 \mathrm{keV}$ & “ & \\
34 & $159-374 \mathrm{keV}$ & “ & \\
35 & $374-972 \mathrm{keV}$ & “ & \\
36 & $972-1885 \mathrm{keV}$ & & \\
37 & $1885-4007 \mathrm{keV}$ & & \\
\hline & & &
\end{tabular}

levels, the spectral characteristics of the particles are also often altered (e.g., Christon et al., 1989, 1991; Ono et al., 2009). Knowledge about the concurrent solar wind conditions and the interplanetary magnetic field is therefore important when discussing processes and mechanisms responsible for energization and diffusion processes leading to spectral changes.

In the present study, we have utilized a specially prepared OMNI data set (available from http://cdaweb.gsfc.nasa.gov/ istp_public/) where solar wind measurements from various solar wind monitors have been time shifted according to the method originally proposed by Weimer et al. (2003) and later refined by Weimer and King (2008). Basically, this method tries to establish the orientation of the IMF phase front at the position of the solar wind monitor, and then use the solar wind velocity to estimate the arrival of this phase front at the Earth's magnetopause or bow shock where the interaction takes place.

\subsubsection{Geomagnetic disturbance indices}

To study correlations between the spectral shape and geomagnetic activity, our data set also contains set of indices characterizing various processes in the magnetosphere. The Dst (Disturbed Storm Time) index is a measure of the 


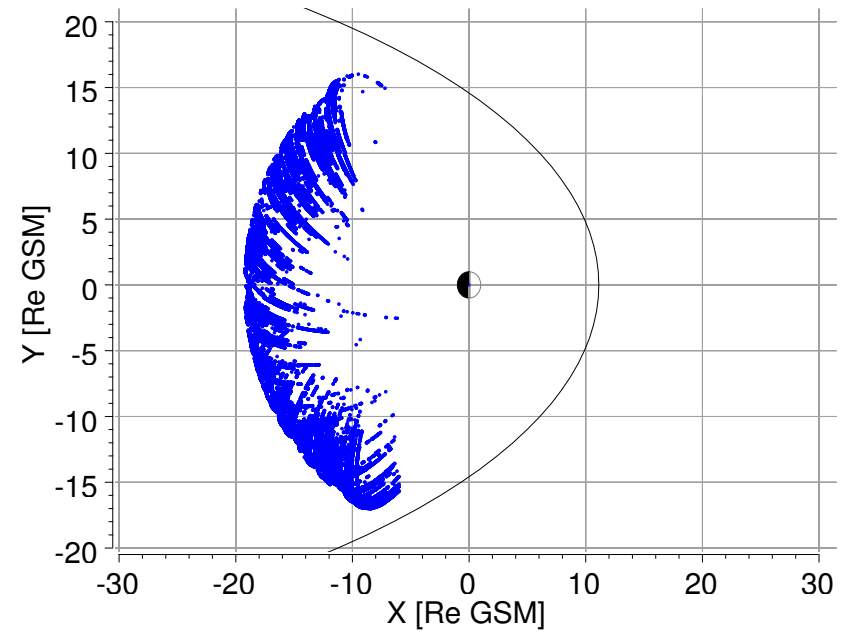

Fig. 1. Spatial coverage of the data set. The majority of the measurements are obtained near Cluster's apogee at $18 R_{\mathrm{E}}$, and within local times $\simeq 19: 00-05: 00$.

horizontal magnetic deflection on the Earth at equatorial latitudes. Negative deflections in Dst are mainly controlled by the Earth's ring current and the cross-tail current, though the solar wind pressure also contributes (e.g., Burton et al., 1975; O'Brien and McPherron, 2000). Positive deflections are usually caused by pressure enhancements in the solar wind which cause a displacement of magnetopause. The Dst index was provided in digital form by the World Data Center for Geomagnetism, Kyoto, and resampled and interpolated to one minute time tags of the Cluster data using the method described in Schwartz (1998).

The Auroral electrojet (AE) index, is a measure of the horizontal magnetic deflection at auroral latitudes. It is supposed to reflect auroral geomagnetic activity, primarily associated with tail magnetic activity such as substorms (Rostoker et al., 1980) and bursty bulk flow events - i.e., short periods of fast plasma flow, presumably associated with small, localized reconnection events (e.g., Angelopoulos et al., 1994). However, the longitudinal coverage of AE observatories is incomplete so localized substorm activity may sometimes escape detection. The AE index was also obtained at one minute resolution from WDCA.

\subsubsection{Data coverage and characteristics}

All of the above data products; Cluster particle data, IMF and solar wind data, geomagnetic activity indices as well as time tags and spacecraft positions, were put on a common timeline with one-minute resolution. We only consider Cluster measurements obtained tailward of $6 R_{\mathrm{E}}$, and only during the months July to October Fig. 1 shows an $\mathrm{XY}_{\mathrm{GSM}}$ projection of the orbit segments where the central plasma sheet measurements were obtained.

If there is a mode shift in one of the instruments during the one minute accumulation period, we discard that record - the data set is therefore not continuous in time. In the early part of the Cluster mission, there were also telemetry constraints which prevented full coverage. The total data set consist of approximately 330000 one-minute records, corresponding to $5400 \mathrm{~h}$, from the years 2001 to 2004 . From this full data set we then extract subsets within certain parameter ranges to address various issues as discussed in the next section.

We are primarily interested in the long-term average descriptions of the energy spectra in the plasma sheet for various magnetospheric states. With all measurements on a common one-minute timeline, we proceed as follows to produce such characteristic spectra; First we make sure that we only include measurements from the plasma sheet. Data from e.g., spurious incursions into the lobe are discarded by removing records below a certain $\beta$ threshold (see Sect. 2.2). From the remaining records we then accumulate particle measurements over several one-minute records, i.e., as a measure of characteristic flux in a particular energy channel we use the aritmetric mean of a number of individual one-minute flux values for that energy channel. As with any averaging, this procedure is effectively a low pass filtering which removes spectral variations on short time scales, whereas persistent features in the spectra will be conserved.

\subsubsection{Accuracy and statistical spread}

In addition to uncertainties in the cross calibration between the two instruments (see Sect. 2.1.3 and Kronberg et al., 2010), there are two main sources of uncertainty in our study: 1) Identification of plasma regime; 2) Statistical spread in the RAPID and CIS count rates. Other errors such as energy binning, timing errors in the solar wind propagation (e.g. Mailyan et al., 2008) etc. are believed to be small in comparison.

As explained in detail in the next section, determination of plasma regime is primarily based on the plasma $\beta$, obtained from the CIS moments and FGM measurements, respectively. Plasma temperature and density entering the $\beta$ calculation are based on the CIS part of the distribution only (due to the lack of sensitivity in the central RAPID sensor, we are not able to include higher energies in the $\beta$ calculation). The use of such partial distributions can lead to an underestimation of density and temperature, and thus a lower estimate of $\beta$ than the real value. We have here only used moments from instrument modes recommended by the instrument team (Dandouras and Barthe, 2007). Another, and probably more important issue with $\beta$ is the definition of thresholds to identify the various plasma regimes. This is discussed in Sect. 2.2.

Whereas the statistical uncertainty (standard deviation) for a single sample (one spin) can be quite high, in particular for the RAPID instrument where the count rates are sometimes very low or even zero, the averages presented here typically consist of several tens or several hundred hours of data. As an estimate of the statistical spread in these long time averages, 
we have therefore used the mean absolute deviation (MAD):

$$
\mathrm{MAD}=\operatorname{median}(|f(i)-\operatorname{median}(f(i))|)
$$

where $f(i)$ is the long-time average flux in energy channel $i$.

Here, MAD describes the median deviation from the most probable non-zero value in a distribution. MAD is a more robust (in the sense that it insensitive to departures from the assumptions about a specific distribution) measure of the spread in a univariate data set. Unlike e.g., the standard deviation, the presence of outliers (e.g., zero counts in the upper RAPID channels) thus does not change the value of the MAD. More information about MAD can be found in text books about statistics, e.g., Venables and Ripley (1999, Chapter 5).

\subsection{Determination of plasma regime}

When comparing spectral information, one obviously want to make sure that the data are obtained from the same plasma regime. Depending on purpose and available measurements, several methods to identify a particular plasma regime are conceivable.

Baumjohann et al. $(1988,1989)$ used the spacecraft charging effects to distinguish between lobe and the plasma sheet (PS) and plasma sheet boundary layers (PSBL). The idea is that artificially high electron densities are caused by inclusion of photoelectrons. In the CPS, the plasma density is generally higher, and spacecraft charging will be less pronounced. They classified any periods where the ratio between electron and proton densities, $N_{\mathrm{e}}>0.94 N_{\mathrm{p}}^{0.86}$ as PSBL. Samples with $\left.B_{T}=\sqrt{(} B x^{2}+B y^{2}\right) \leq 15 \mathrm{nT}$ or $B_{z} / B_{T} \geq 0.5$ were used to identify the inner central plasma sheet, regions outside this range were classified as "outer central plasma sheet". The actual $\beta$ values in their data set varied from 0.3 in the outer central plasma sheet up to 30 near the neutral sheet.

Cluster has an active spacecraft voltage control (ASPOC - see Torkar et al., 2001), so methods based on spacecraft charging are excluded. Also methods based on energy density (e.g., Ono et al., 2009) were discarded. In this study we have instead chosen used a combination of spacecraft position, plasma $\beta$ and the plasma bulk velocity to determine whether a particular sample is taken in the central plasma sheet (CPS), plasma sheet boundary layer (PSBL) or the tail lobes.

In particular during disturbed periods, the plasma sheet is subject to wave activity and flapping which leads to sporadic entries of the spacecraft into the lobes. In contrast to the plasma sheet, the lobes are almost devoid of energetic particles, and only a very diluted population of cold plasma. Lobe encounters are therefore easily recognizable in the data, but moment calculations are not reliable due to the low density. To identify and exclude samples from the lobes, we have therefore used a low, and very conservative $\beta$ threshold.
Table 2. Plasma $\beta_{i}$ thresholds used to determine plasma regimes. See also Table 1 of (Åsnes et al., 2008).

\begin{tabular}{llcc}
\hline & Region & $\beta_{i}$ & Remarks \\
\hline CPS & Central plasma sheet & $>0.70$ & \\
PSBL & Plasma sheet boundary layer & $0.01-0.2$ & $|V x|>75 \mathrm{~km} / \mathrm{s}$ \\
LOBE & Magnetotail lobes & $<0.01$ & \\
\hline
\end{tabular}

A similar approach to classify plasma regions has been used by earlier Cluster based studies (e.g., Ruan et al., 2005; Åsnes et al., 2008), although with different thresholds for the various regimes, and sometimes a finer division of the regimes. Table 2 shows details about the $\beta$ thresholds and criteria used for the initial classification.

In most cases, we found little difference in the spectral shape between the CPS and PSBL, but unless explicitly stated, the following results are based on all measurements tailward of $\mathrm{X}_{\mathrm{GSM}}=-6 R_{\mathrm{E}}$ with $\beta \geq 0.7$, and where the distribution can be expected to be fairly isotropic. Note also that our $\beta$ threshold is more conservative than those of Baumjohann et al. (1989). We also discarded records where the CIS or RAPID instrument had zero counts or fillvalues in two or more of the energy channels.

\subsection{Characteristic spectra}

A particle population is often described statistically in terms of its velocity distribution or energy spectra. In the ideal case, and without any external forces the particles will attain a Maxwellian velocity distribution. For a given particle species, the omnidirectional differential flux as function of energy will then $f(E)=A \frac{E}{E_{0}} e^{-\frac{E}{E_{0}}}$, where $A$ is a constant, $E$ is the kinetic energy, and $E_{0}$ is the characteristic energy (the energy with maximum flux) of the population.

However, in space, particles can be accelerated (energized) by various processes. Depending on the process, the whole population, or just parts of the population are energized. The former will shift the distribution, whereas the latter will alter the spectral shape. Energy shifted spectra are consistent with e.g., electrostatic acceleration or convective flow. Other acceleration processes (see e.g., review by Blake and Slavin, 1998 , or references therein) or inflow of particles from other regions of space (from e.g., reconnection regions or penetration of interplanetary fluxes), on the other hand, will typically alter the spectral shape. Similarly, de-energization or diffusion processes can also alter the spectral shape.

In the magnetosphere, there will often be an excess of particles with energies above the characteristic energy. The spectra is then said to have a high energy tail. One such model distribution can be described by a power law, $f(E)=$ $A E^{-\gamma}$, where $\gamma$ determines how hard (excess of high energy particles) or soft the spectra is. 


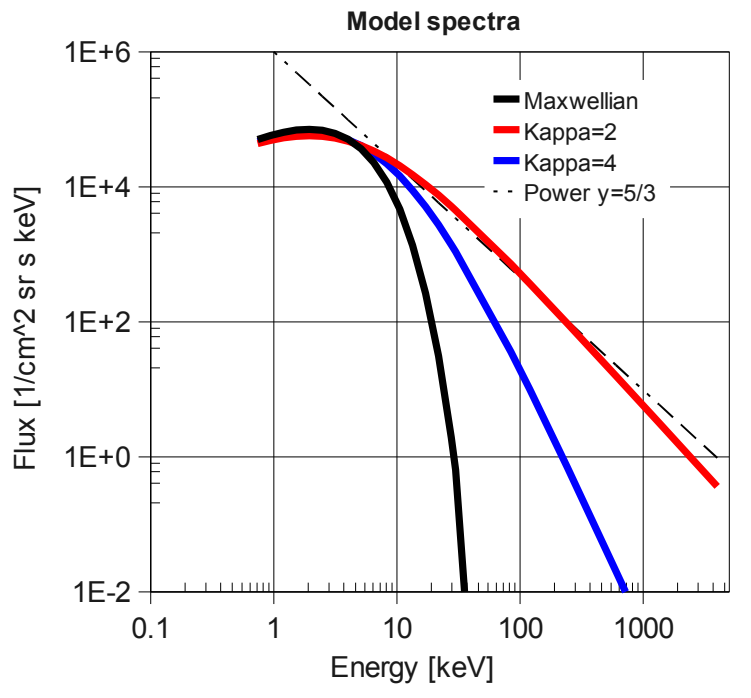

Fig. 2. Functional forms of different spectra used to describe a particle population. The $\kappa$ distribution is essentially a Maxwellian for low energies combined with a power law spectra for higher energies.

Another frequently used model spectra is the $\kappa$ (Kappa) distribution, where the flux as a function of energy is described by:

$f(E)=A E\left[1+\frac{E}{\kappa E_{0}}\right]^{-\kappa-1}$

where $\kappa$ is the spectral index (spectral slope) - a measure of how quickly the spectrum falls off at higher energies. Large values of of $\kappa$ indicate a Maxwellian like distribution (for $\kappa \rightarrow \infty$ we have an Maxwellian distribution), whereas low $\kappa$ values indicate a high energy tail (hard spectra).

A Maxwellian distribution is sometimes referred to as thermal, whereas the distributions with a high energy tail are referred to as supra-thermal. Figure 2 shows characteristic energy spectra for the Maxwellian, a power law and two kappa distributions.

\section{Results}

\subsection{Case examples: geomagnetic storms}

Geomagnetic storms are disturbances in the geomagnetic field caused by the interaction between the solar wind and the Earth's magnetosphere (see e.g., Gonzalez et al., 1994; Kamide et al., 1997, and references therein). During storms, charged particles in the plasma sheet are energized and transported into the inner magnetosphere, enhancing the ring current which causes deflections in the magnetic field and thus a response in the Dst index (Nosé et al., 2005). (There are also other contributions to the Dst index - see e.g., Campbell, 1996; O'Brien and McPherron, 2000; Turner et al., 2000).
Table 3. Key parameters during the three highlighted time intervals in Fig. 3.

\begin{tabular}{lccc}
\hline Storm phase/interval & Dst [nT] & AE [nT] & Kp \\
\hline Before (17-20 Jul) & -6 to -47 & 30 to 670 & $1-$ to $2+$ \\
During (24-27 Jul) & -32 to -181 & 82 to 2163 & $1+$ to $8+$ \\
After (31 Jul-3 Aug) & -24 to -46 & 29 to 601 & $0+$ to $4-$ \\
\hline
\end{tabular}

During the years 2001-2004 covered by this study, 13 geomagnetic storms with minimum Dst values below $-100 \mathrm{nT}$ took place. Cluster's $57 \mathrm{~h}$ polar orbit is not ideally suited for studies of long time processes in the central plasma sheet. Therefore, we do not have a continuous coverage of all phases of any of these storms, but use subsequent Cluster passages during the nightside plasma sheet to get snapshots of the various storm phases.

\subsubsection{Event 1: July 2004 geomagnetic storms}

One event where we have reasonable data coverage took place in July 2004. For this event (actually a series of 3 intensifications), we are able to get good measurements at various phases the storm. Figure 3 shows an overview of the Dst index and spectral response for this period. Note that the observations within these three intervals are not necessarily continuous, primarily since the plasma $\beta$ criterium (see Sect. 2.2) is not always satisfied for the full intervals.

Following a sudden commencement on 22 July 2004, the Dst drops to $-101 \mathrm{nT}$ on 23 July, followed by a second minima of $-147 \mathrm{nT}$ on 25 July. A third intensification follows a few days later, and the Dst index reaches $-197 \mathrm{nT}$ around noon on 27 July. Cluster was in the nightside plasma sheet during the two latter of these intensifications. Table 3 shows a summary of the key parameters during the observations of this storm. (Note that we do not have observations during the absolute minimum Dst).

Although the most pronounced manifestations of a geomagnetic storm are typically found closer to Earth, we also observe changes in the energy spectra further tailward where Cluster crosses the central plasma sheet for this case. The lower panels of Fig. 3 show average ion spectra obtained in the central plasma sheet $(\beta \geq 0.70)$ before, during and after the storm, respectively. Each spectrum shown is produced by averaging a number of individual one-minute records (we also tested median instead of mean values, but we found no significant difference between these two methods to represent averages). The approximate sampling periods for the three storm phases are indicated in the Dst time plot in Fig. 3. Note that the samples are not continuous in time, primarily because the plasma sheet moves, contracts and expands so that Cluster enters and exits the central plasma sheet several times. To facilitate comparison between the different spectra, we also add a model $\kappa$ spectrum with $\kappa=5$ and $E_{0}=3 \mathrm{keV}$ 


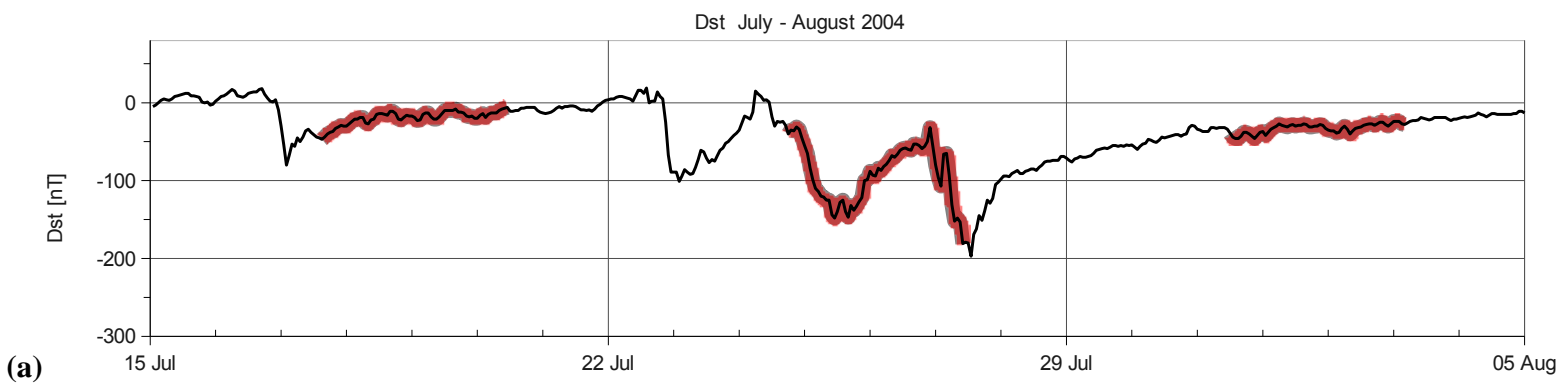

(a)
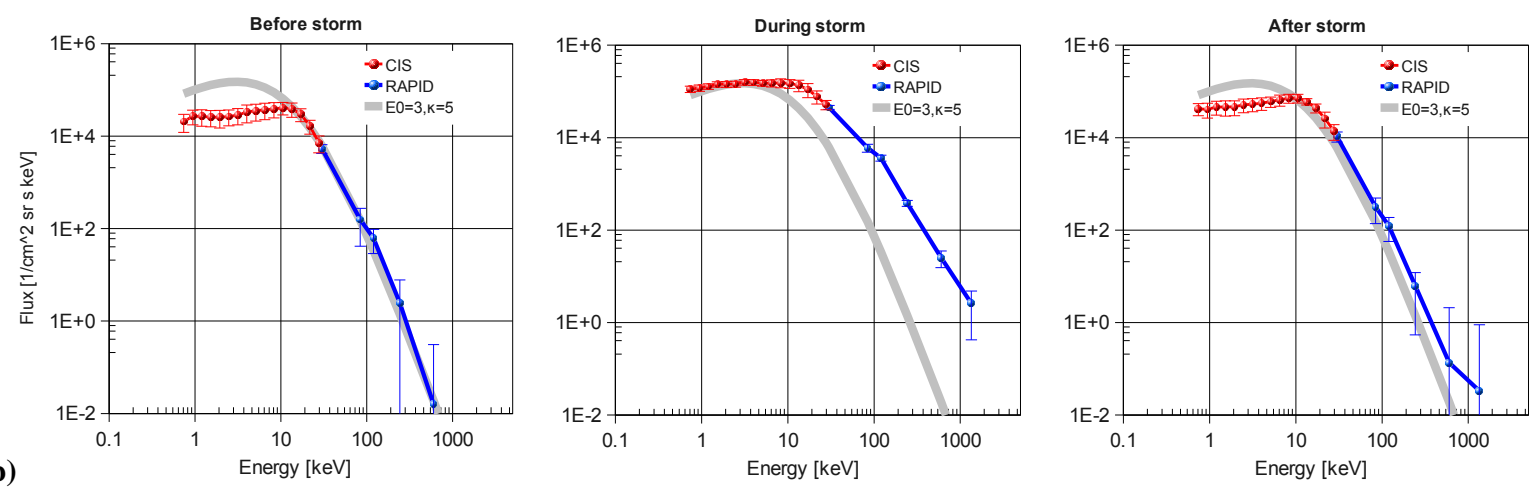

Fig. 3. Ion energy spectra during three phases of two geomagnetic storms. Panel (a) Dst values during 15 July-5 August 2004 . Highlighted time intervals indicate periods (Cluster orbit segments during central plasma sheet crossings, though not necessarily continuous measurements) used to generate the characteristic spectra in the lower part of the figure. Panel (b) Energy spectra before, during and after the geomagnetic storms on 22-28 July. The dots represent the average proton flux (vertical axes) for each energy channel (horizontal axes) of the RAPID (plotted with blue color) and CIS (red) instrument. Each dot is drawn at the logarithmic center of the respective energy channel (see Table 1), and the error bars indicate the median absolute deviation (MAD - see Eq. 1). To facilitate comparison between the different spectra, we also add a model $\kappa$ spectrum with $\kappa=5$ and $E_{0}=3 \mathrm{keV}$ (gray, solid line) to all spectra in this row.

(gray, solid line). This model spectrum is a visual fit to the high energy part of the lower left spectrum.

The lower left panel shows the characteristic energy spectrum prior to the storm (to get sufficient statistics, this average also contains some data points from the recovery phase of a preceding smaller storm on 16-17 July). This spectrum is an average of approximately 450 one minute records $(7.5 \mathrm{~h}$ of accumulated data). The average Dst is $-12 \mathrm{nT}$, and the average AE index is $190 \mathrm{nT}$ during this period. During this interval, we observe a fairly soft spectra with a spectral slope $\kappa \simeq 5$.

During the storm (lower middle panel), we use another 450 samples to generate an average storm time spectrum. The average Dst index for this time interval is $-59 \mathrm{nT}$, with a few records having Dst values below $-180 \mathrm{nT}$. The corresponding average $\mathrm{AE}$ index is $510 \mathrm{nT}$, indicating significant auroral activity. In this interval, we observe a much harder spectra, with $\kappa \simeq 3$ and a shift towards higher characteristic energy $E_{0}$.

After the storm (lower right panel) most of the high energy tail subsides; $\kappa$ returns to a value $\simeq 5$, and the characteristic energy eventually resides to lower values again.

The remanent flux in the highest RAPID channel seen in the rightmost spectra in Fig. 3 may be due to penetra- tion of interplanetary particles. In a case study, Christon et al. (1989), demonstrated that the energy spectrum for $E \geq 100 \mathrm{keV}$ ions was dominated by an interplanetary population. Indeed, measurements of energetic fluxes from the Electron, Proton, and Alpha Monitor (EPAM - see Gold et al., 1998) onboard the ACE spacecraft located in the solar wind, reveal a pronounced, dispersive increase in energetic particle flux starting around 12:00 UT on 31 July 2004. A similar signature, although less pronounced is observed in $E \geq 100 \mathrm{keV}$ ions at the WIND spacecraft, also located in the solar wind. These dispersive events are most likely caused by interplanetary shock accelerations in the solar wind.

\subsubsection{Event 2: September 2002 geomagnetic storms}

A similar sequence of two geomagnetic storms took place in September 2002. An overview of the Dst index and the corresponding spectra are shown in Fig. 4. Due to the polar orbit of Cluster, the coverage was not optimal during the main phase of any of these storms, but the general response was very similar to the above July 2004 event; Initially, we observe a fairly soft average spectrum (i.e., closer to a Maxwellian, but still with a high energy tail and $\kappa \simeq 5$ ). During the storm main phase, there seems to be a significant 


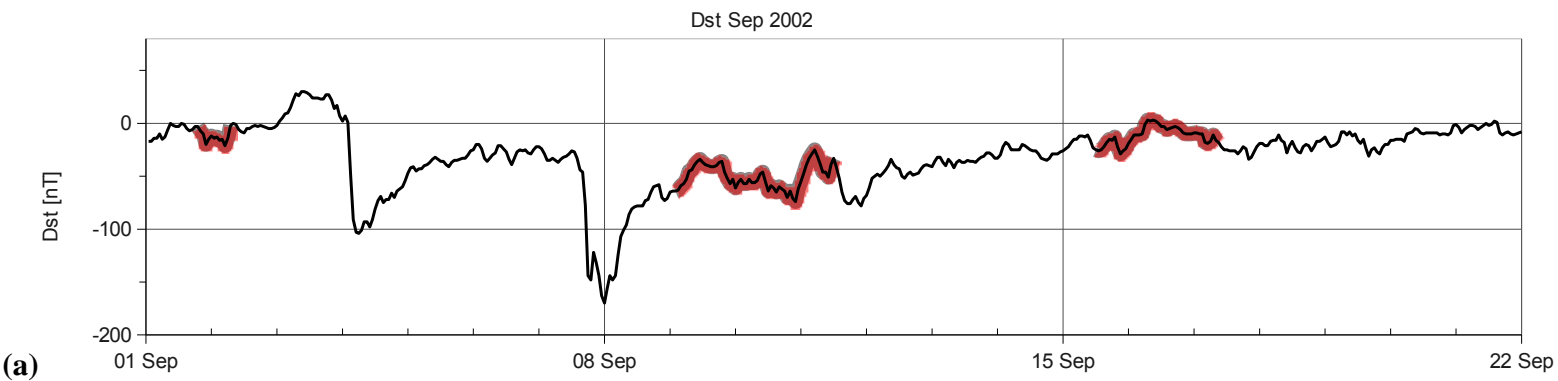

(a)
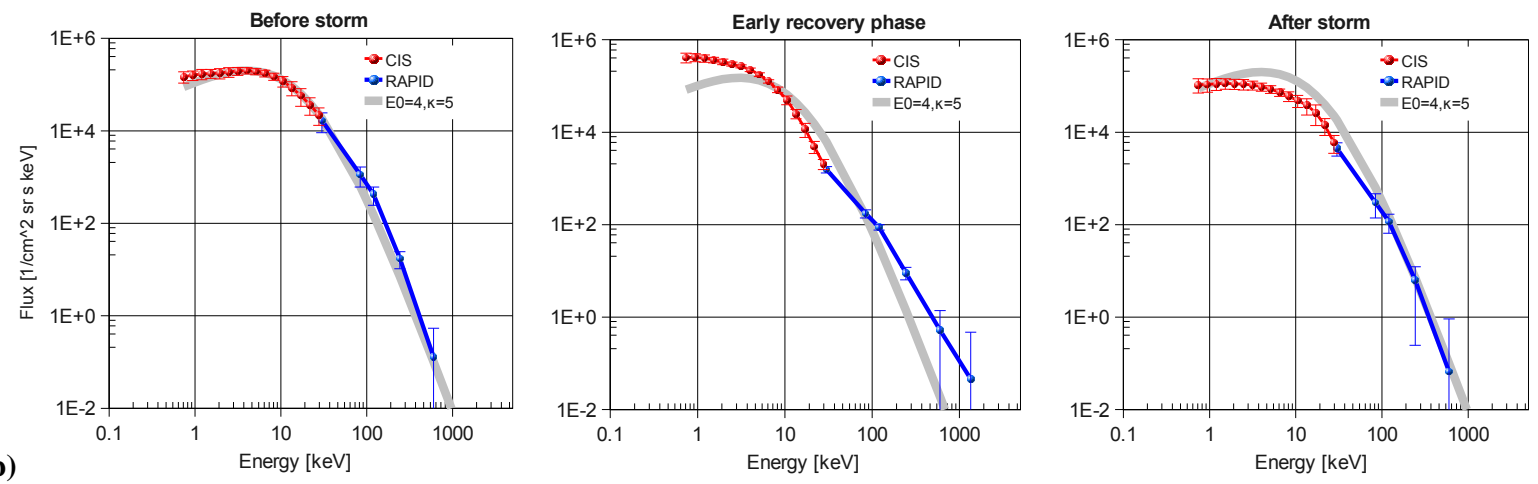

Fig. 4. Same as Fig. 3, but for two geomagnetic storms in September 2002. There were no Cluster observations satisfying our criteria during neither of the main phases of the storms for this case.

Table 4. Key parameters during the September 2002 geomagnetic storms. The intervals are those highlighted in the upper part of Fig. 4.

\begin{tabular}{lccc}
\hline Storm phase/interval & Dst [nT] & AE [nT] & Kp \\
\hline Before (1-2 Sep) & -1 to -23 & $117-824$ & 2- to 4o \\
Recovery (9-11 Sep) & -32 to -181 & $25-1457$ & $0+$ to 5o \\
After (15-17 Sep) & -3 to -27 & $15-845$ & $0+$ to 3o \\
\hline
\end{tabular}

acceleration and heating which produce a much harder spectrum (lower spectral slope, $\kappa$ ) which is still observed in the [early] recovery phase. A few days later, the distinct high energy tail of the distribution has subsided again.

The key observations during the three investigated intervals are given in Table 4.

Our results for these two case studies thus seem to be more in line with the ISEE results of Christon et al. (1991) and recent Geotail results reported by Ono et al. (2009), who also found a significant correlation between the spectral slope and the activity level. On the other hand, (Christon et al., 1991) also pointed out that whereas the characteristic energies, $E_{0}$ had a similar behavior for both ions and electrons, the spectral slopes of ions and electrons respectively, did not respond in the same way to increased disturbance levels. One should also keep in mind the ISEE measurements in Christon et al. (1991) did not distinguish between ion species. In particular during disturbed periods, the abundance of heavier ions in- crease significantly (e.g., Young et al., 1982; Fu et al., 2002). Simulations (e.g., Delcourt et al., 1990; Sanchez et al., 1993) and observations (e.g., Moebius et al., 1987; Nosé et al., 2000) indicate that oxygen are energized more than protons during high geomagnetic activity.

\subsection{Statistical results}

To study the average influence of the various driver parameters, spacecraft location, geomagnetic activity, plasma regime etc., we extract subsets of the complete data set, and generate average spectra from these subsets. Unlike the case example above, we now use the full 4-year data set to form the averages. We also compare some of our results with the findings of Åsnes et al. (2008), who studied the statistical properties of RAPID electron measurements.

\subsubsection{Response to geomagnetic activity}

Earlier studies have shown that the Earth's plasma sheet undergo dramatic changes during disturbed geomagnetic periods (e.g., Baumjohann et al., 1990, and references therein). During the growth phase of a substorm, for example, the whole plasma sheet becomes much thinner, and the magnetic field becomes more stretched. During the expansion phase, the ion density decreases while the temperature typically increases.

Åsnes et al. (2008) found that on average, the spectral slope of electrons in the energy range $40-400 \mathrm{keV}$ did not 

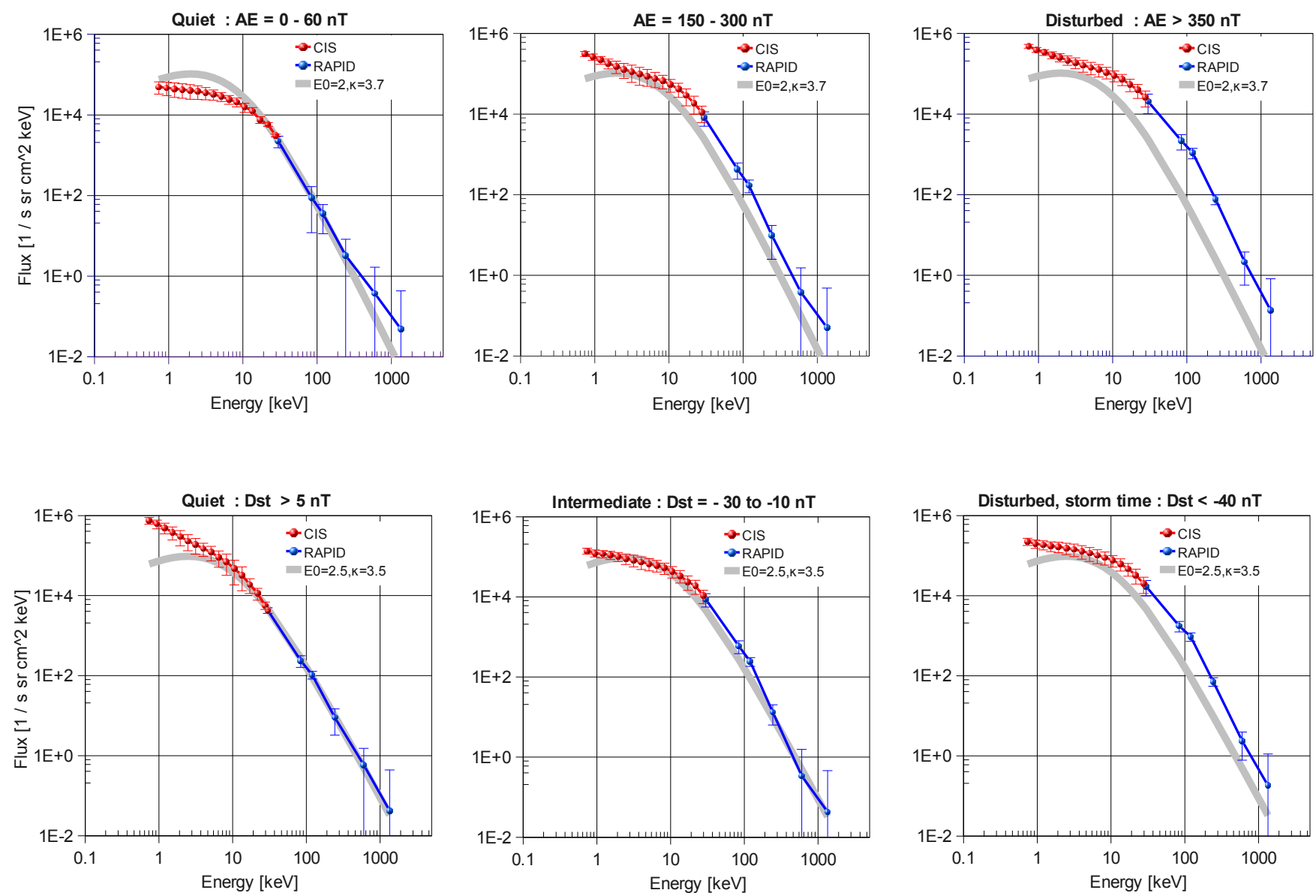

Fig. 5. Statistical proton spectra as function of geomagnetic activity. Top panels: spectrum during period with low (left), intermediate and high (right) AE index. Bottom panels: spectrum during quiet (positive Dst values - left), intermediate Dst values (center panel) and stormtime (large negative Dst - right panel) conditions. Data for the years 2001-2004 have been used to produce these averages. The gray curve represents a visual fit to the high energy part of the leftmost spectrum in each row.

respond very much to geomagnetic activity. Their conclusion was based on the lack of response in the average spectral slope to changes in the Kp index. Our data set, on the other hand, contains the $\mathrm{AE}$ and Dst indices as proxies for disturbance. As a rule of thumb, one can say that the AE index reflects fast, intermittent changes in the plasma sheet, such as bursty bulk flow events with time scales of minutes, and substorm activity with time scales of a few hours. The Dst, which is mainly a proxy for the Earth's ring current, on the other hand reflects longer time intervals, typically several days. However, Dst and AE are strongly correlated; the largest $\mathrm{AE}$ values are typically observed during geomagnetic storms (Kamide et al., 1998).

Parts of the discrepancies between our case results above and those of Åsnes et al. (2008) may have to do with the disturbance proxy used; The Kp index used by Åsnes et al. (2008) is a $3 \mathrm{~h}$ index. Since the plasma sheet sometimes gets extremely thin during disturbed conditions (see e.g., Sanny et al., 1994; Pulkkinen et al., 1999; Sergeev et al., 2008),
Cluster often completely crosses or enters and exits the central plasma sheet several times within the $3 \mathrm{~h}$ interval used to determine the $\mathrm{Kp}$. The minor difference in $\beta$ criteria for identifying the central plasma sheet between the present study and that of Åsnes et al. (2008) sheet does not play any role. Indeed, including only samples with $\beta \geq 1$ revealed only very minor effects on the spectral response to the two storm examples discussed above.

Whereas we find a noticeable response in the spectral slope to geomagnetic activity if we consider individual storms or time intervals, long term, statistical observations moderate this result. This is true both for long time processes (geomagnetic storm time scales - reflected by the Dst index) and shorter time scales (reflected in the AE index). Figure 5 shows average spectra for three different ranges of the Dst and $\mathrm{AE}$ indices. These ranges represent quiet, moderate and disturbed periods for the respective indices. As for the case example above, we also show a model fit to easier facilitate comparison between the different spectra. 

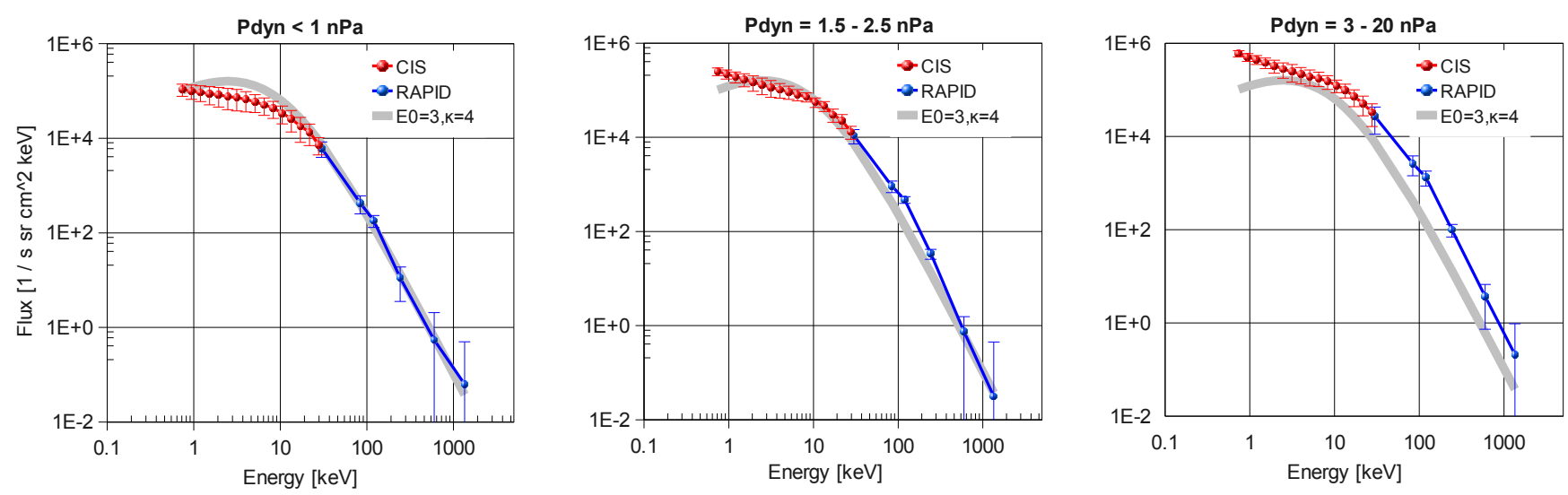

Fig. 6. Average proton spectrum for low (left panel), intermediate (center panel) and high (right panel) solar wind dynamic pressure. As for the other figures, gray curves represent a visual fit to the high energy part of the Pdyn $=0-1 \mathrm{nPa}$ spectrum. The most notable response is a change towards higher characteristic energies for higher solar wind pressure.

In the upper part of Fig. 5 we show the response in three different non-overlapping AE ranges. These spectra are based on averages during the years 2001-2004, and contains 166, 171 and $158 \mathrm{~h}$ of accumulated data inside the central plasma sheet, respectively. The most pronounced response is the shift in characteristic energy towards higher energies during disturbed periods; the flux increases over a wide energy range. The spectral slope, on the other hand, does not change significantly, and $\kappa$ remains around 3.5-4 regardless of the $\mathrm{AE}$ value.

A similar behavior can be seen if we sort our data according to the Dst index. The three Dst ranges shown contain 118, 198 and $132 \mathrm{~h}$ of data respectively. Once again, the most pronounced response is a shift in characteristic energy towards higher energies during disturbed periods, with little or no response in the spectral slope.

The majority of Cluster plasma sheet crossings take place near apogee around $16-20 R_{\mathrm{E}}$. This location is not optimal for studying large scale magnetic field reconfigurations associated with substorms, since these are typically more pronounced closer to Earth. The shift in characteristic energy rather than a change in the spectral slope, is also an indication of bulk transport of plasma rather than a energy dependent acceleration. The main reason for the AE dependency seen in Fig. 5 is therefore most likely related to bursty bulk flow activity.

The seemingly different behaviour observed between the two case studies and the statistical analysis may be coincidental, but it also reminds us that ground based indices such as $\mathrm{AE}$ and Dst are only able to provide a partial description of the magnetotail processes. Only if we limit the data set to extreme values of the $\mathrm{AE}$ and Dst indices we are able to reproduce some of the spectral behavior as seen in the storm case example in the previous section.

\subsubsection{IMF and solar wind dependence}

One of the advantages of our data set compared to similar studies from earlier missions, is the availability of nearly continuous solar wind observations. Combined with better methods to time shift the ACE observations from the L1 libration point to the Earth's upstream magnetopause, we are in a better position to address the response in the plasma sheet to changes in the solar wind and IMF.

To check for such responses, we first created subsets containing samples taken during periods of very low, intermediate and high solar wind dynamic pressures. Records with data gaps in the solar wind data were discarded. The spectra for each subset are shown in Fig. 6. The three data sets contain approximately 312,127 and $22 \mathrm{~h}$ of accumulated data respectively.

During periods with high solar wind dynamic pressure, the characteristic energy increases and the overall flux becomes slightly higher. The latter can possibly be related to a compression of the magnetosphere which leads to a small increase in overall density. There are also secondary effects; periods of high solar wind pressure are typically associated with higher geomagnetic activity, and some of the effects discussed in the previous sections also affect the spectral slope (for an assessment of the mutual dependencies between different driver parameters such as IMF orientation, solar wind pressure, AE, Dst etc., see Table 1 of Förster et al., 2007). It is therefore difficult to assess the direct response in particle energization to increased solar wind pressure.

Our data set allows for sorting according to IMF direction. Whereas there are obvious differences in the spectral characteristics for northward IMF versus southward IMF, which can be attributed to the geo-efficiency, we do not find significant dependence on IMF Bx or IMF By.

In order to check whether interplanetary fluxes could penetrate the magnetosphere and show up in the RAPID 

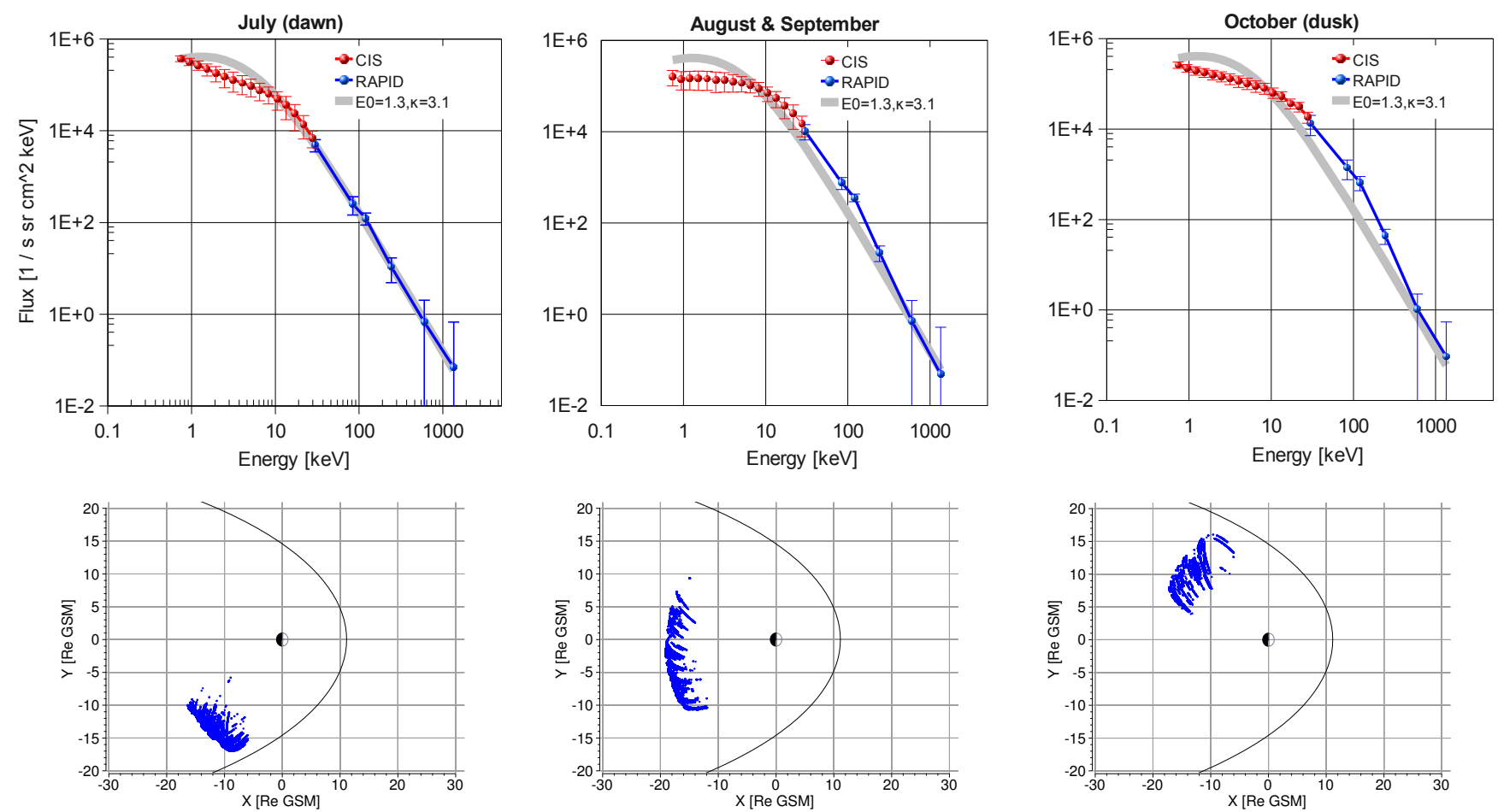

Fig. 7. Seasonal dependence of average energy spectra. Top left panel: Average spectrum for the dawn side (measurements from July only). Top center panel: Average spectrum for the 22:00-02:00 local time sector (measurements from August and September crossings only) Top right panel: corresponding spectrum for the dusk side (measurements from October only). The gray curve in the top panels represents a visual fit to the high energy part of the July spectrum. The lower panels show $\mathrm{XY}_{\mathrm{GSM}}$ projections of the orbit segments where the respective average spectra were obtained.

measurements, we visually inspected the Low Energy Magnetic Spectrometers (LEMS) onboard the ACE spacecraft (Gold et al., 1998). This instrument measures the flux and direction of ions in 8 energy channels and the energy range $47 \mathrm{keV}-4.75 \mathrm{MeV}$. Whereas the high energy seen in the RAPID data in the storm case discussed in Sect. 3.1.1 may have been attributed to interplanetary penetration, we found no clear connection between the energetic ion fluxes at ACE and the ion fluxes observed by Cluster in the central plasma sheet. Even if such a connection could be established, the cause-versus-result issue would still be ambiguous. Scholer et al. (1981) and Desai et al. (2009) have demonstrated that energetic ions of magnetospheric origin could be the source of enhanced fluxes observed upstream of the Earth's bow shock rather than the other way around.

\subsubsection{Local time dependence}

An interesting result reported by Åsnes et al. (2008), also using Cluster data from the same period as this study, was that the electron spectra was harder on the dawn side, which could indicate that the high energy part of the electron distribution gets accelerated as it drifts towards dawn. Similar results were also been reported by e.g., Meng et al. (1981) and Sarafopoulos et al. (2001), but at different radial distances.
To check whether the protons show a similar behavior, we compare the average spectra obtained in July (when Cluster traverses the plasma sheet in the post-midnight sector, i.e., dawn) with corresponding data set comprising of measurements from October (pre midnight traversals, i.e., dusk). For completeness, we also show plasma sheet averages from the 22:00-02:00 local time sector, crossed by Cluster during $\mathrm{Au}-$ gust and September.

The average spectra for these three regions are shown in Fig. 7. These results are based on approximately $324 \mathrm{~h}$ of data for the dawn side, $240 \mathrm{~h}$ in the 22:00-02:00 local time sector and approximately $161 \mathrm{~h}$ of data from the dusk side. If we consider the full energy range of the RAPID instrument, our results show a nearly identical slope for all three regions, although the fluxes in the energy range $\simeq 15 \mathrm{keV}$ to $\simeq 500 \mathrm{keV}$ are significantly higher on the dusk side.

A theoretical argument for a local time asymmetry is that energetic ions gain a considerable amount of their energy from the cross-tail electric field. One should then observe higher fluxes of the energetic part of the spectra near the dusk side. This argument was also mentioned by Åsnes et al. (2008) (though reversed dawn-dusk asymmetry since they discussed electrons), and also by Meng et al. (1981) and Sarafopoulos et al. (2001). However, we note that the 
geomagnetic conditions, reflected by the Dst index, is more disturbed during the dusk traversals (average Dst is $-35 \mathrm{nT}$, versus $-8 \mathrm{nT}$ for the dawn side), so this apparent effect does not seem to be solely a local time dependence, but also an effect of different average geomagnetic activity for the two sides. The latter can possibly be partially understood from the Russell-McPherron effect, which explains it in terms of geo-efficiency. Essentially, the solar wind-magnetosphere coupling is more efficient for certain dipole tilt orientations (Russell and McPherron, 1973). For Cluster traversals of the dusk side (October) the geo-efficiency is higher then for the traversals in the dawn sector (July).

A further sub-filtering so that the spectra from the three regions only included records with Dst in the range -30 to $0 \mathrm{nT}$ (the average Dst values of this subset were $-10 \mathrm{nT}$ in July, $-13 \mathrm{nT}$ in August-September and $-13 \mathrm{nT}$ in October, respectively), revealed very similar spectra, with spectral slopes $\kappa \simeq 3.9$ for all three regions. The actual flux values are still somewhat higher for the dusk sector though.

Due to the orbit of Cluster, we only have data from radial distances between 16 to $20 R_{\mathrm{E}}$. Within this limited range, we do not find any distinct correlations between spectral slope and radial distance.

\section{Summary and discussion}

Based on proton measurements in the energy range $700 \mathrm{eV}-$ $2 \mathrm{MeV}$ from the Cluster RAPID and CIS instruments in the Earth's nightside plasma sheet at radial distances between 16-20 $R_{\mathrm{E}}$, we have investigated the statistical behavior of the energy spectra for various geomagnetic conditions, with a special emphasis on the energetic part of the distribution.

As in many earlier studies, we also find a significant deviation from a Maxwellian distribution for the higher energies. Visual fits of the spectra reveal spectral slopes typically in the range $\kappa=6$ to 3 , primarily depending on geomagnetic activity, thus corroborating earlier results from similar radial distances presented in e.g., Christon et al. (1991) and Ono et al. (2009).

In two individual case studies of geomagnetic storms, we found evidence for hardening of the spectra during the main phase the storms. The spectral slopes approached values around $\kappa \simeq 3$ and lower, and for one case, a significant shift in the characteristic energy towards higher energies were observed. However, for the long term statistical studies, a sorting according to the Dst index did not reveal any pronounced change in the spectral slope. In this respect, our results are in agreement with (Åsnes et al., 2008), and also in line with Sarafopoulos et al. (2001) who found very different spectral response between two individual substorms.

For the lower energies, we sometimes see diversions from a purely Maxwellian distribution. One possible explanation for this is the influence of ions of ionospheric origin (e.g., Horwitz, 1982; Chappell et al., 2000): cold ions is a signifi- cant source of plasma for the central plasma sheet where the subsequent energization takes place (e.g., Yau et al., 1985). Some mechanisms, e.g., changes in the convection electric field following rotations of the IMF, can dramatically change the outflow and fluence at a given location almost instantaneously (e.g. Cully et al., 2003; Nosé et al., 2009). Subsequent acceleration in the plasma sheet takes more time. It is therefore expected that the low energy part of the spectrum responds faster and is more variable than the high energy part.

External influences such as solar wind dynamic pressure and/or IMF direction do not seem to have a direct influence on the spectral slope. The $\kappa$ value remains in the range 3.5-4 for a broad range of solar wind dynamic pressures, and there is no direct response in the spectral slope to IMF changes. A shift towards higher characteristic energies are observed during periods with higher solar wind pressure. Possibly except from one case, we did not find any clear correlations between interplanetary ion fluxes and corresponding fluxes measured by Cluster in the plasma sheet.

The lack of direct response in the spectral slope of the energy spectra to IMF or solar wind changes suggests that the high energy tail of the spectra are mainly caused by processes internal to the magnetosphere. Penetration of interplanetary fluxes may be important in some specific cases, but seems to be insignificant for the spectral shape of plasma sheet protons in general.

In contrast to the electron spectra reported by Åsnes et al. (2008), we do not find any distinct difference in the spectral slopes between different local time sectors, but our measurements show higher average fluxes on the dawn side for the energy range $\simeq 10 \mathrm{keV}-500 \mathrm{keV}$. Dawn-dusk asymmetries in flux levels were also found in IMP7 and IMP8 data (Meng et al., 1981 - although they studied radial distances around $30-40 R_{\mathrm{E}}$ ). Sarafopoulos et al. (2001) used a series of $\approx 8 \mathrm{~h}$ averages based on Interball energetic ( 27 to $857 \mathrm{keV}$ ) ion measurements from radial distances between $15-28 R_{\mathrm{E}}$. They found that during geomagnetically quiet times (low Kp values) the ion fluxes in the duskside plasma sheet were much higher than those in the dawn flank, and interpreted the asymmetry as a result of energy dependent drift across the tail that strongly altered the initial distribution. The asymmetry was most pronounced outside $\left|Y_{\mathrm{GSM}}\right|$ beyond $13 R_{\mathrm{E}}$. Our results, on the other hand, only contain few measurements from this region (see Fig. 1), which may explain the lack of a clear dawn-dusk asymmetry.

Various mechanisms have been proposed to explain the hardening and softening of spectra in the magnetosphere (reconnection, wave-particle interaction, diffusion etc.), but most of these mechanisms are still poorly understood. It is also difficult to directly relate a specific mechanism to a response in the energy spectra.

For the magnetotail, and in the tail current sheet in particular, most attempts to explain quiet time non-Maxwellian distributions, focus on the relation between magnetic field 
curvature and gyro radius of the ions (e.g., Büchner and Zelenyi, 1989; Lyons and Speiser, 1982; Speiser and Lyons, 1984; Speiser, 1984; Sarafopoulos, 2008). When the magnetic curvature radius becomes smaller and the current sheet becomes thin compared to the local Larmor radius of the ions, particle motion becomes non-adiabatic. Ions with gyro radius significantly larger than the current sheet thickness would stream along the current sheet from dawn to dusk in a serpentine like motion gaining energy for each half-gyration cycle. This behavior was first discussed in Speiser (1965), and the serpentine like motion is sometimes referred to as Speiser motion. Due to their larger gyro radii, energetic particles are more exposed to current sheet acceleration (Lyons and Speiser, 1982; Speiser and Lyons, 1984), whereas particles with lower energies and thus smaller gyro radius remain adiabatic.

A substantial acceleration is also expected to take place during magnetic reconnection (e.g. Büchner and Kuska, 1998; Wygant et al., 2005; Grigorenko et al., 2009, and references therein) where the ions are accelerated by the reconnection induced electric field. The final energy of the ions depends strongly on their initial position relative to the reconnection site. In the magnetotail, reconnection events are usually manifested as bursty bulk flow (BBF) events short periods with fast flow combined with dipolarization of the magnetic field. The positive correlation between BBFs and disturbance indices (in particular the $\mathrm{AE}$ index) suggests that BBFs predominantly occur during geomagnetic disturbed periods (Angelopoulos et al., 1994).

Particle acceleration can also be produced by dipolarization of the magnetic field (a dipolarization does not necessarily mean reconnection, although the two phenomena are intimately connected in the magnetotail) e.g., in connection with substorms (e.g., Nosé et al., 2000). The time scale of typical dipolarization events are probably to long too directly affect the energy spectrum (Ono et al., 2009), but fluctuations on shorter time scale, comparable to the ion gyro periods can lead to non-adiabatic accelerations (Delcourt et al., 1990).

The observed hardening of the spectra found during the main phase of a storm can most likely be attributed to a combination of all of the above effects. Since the tail current sheet typically gets thinner during storms, additional energization due to Speiser motion can be expected. Acceleration due to increased substorm activity and local reconnection events (e.g., Delcourt, 2002; Mitchell et al., 2003) can also be expected, since such activity is more frequent during storm times. Since our observations are taken tailward of the location where the most pronounced substorm associated magnetic field dipolarizations occur, localized reconnection in association with BBF activity probably plays a larger role for the spectral shape in our cases.
Acknowledgements. Work at the Max-Planck Institute was supported by Deutsches Zentrum für Luft- und Raumfahrt (DLR), grant 50 OC 0801. Research at the University of Bergen was supported by the Norwegian Research Council. Parts of the data analysis were done with the QSAS science analysis system provided by the UK Cluster Science Centre (Imperial College London and Queen Mary, University of London). ACE solar wind and magnetic field data were downloaded from CDAWEB, and the AE and Dst indices were provided by World Data Center for Geomagnetism, Kyoto.

The service charges for this open access publication have been covered by the Max Planck Society.

Topical Editor I. A. Daglis thanks S. P. Christon and two other anonymous referees for their help in evaluating this paper.

\section{References}

Åsnes, A., Friedel, R. W. H., Lavraud, B., Reeves, G. D., Taylor, M. G. G. T., and Daly, P.: Statistical properties of tail plasma sheet electrons above $40 \mathrm{keV}$, J. Geophys. Res., 113, A03202, doi:10.1029/2007JA012502, 2008.

Angelopoulos, V., Kennel, C. F., Coroniti, F. V., Pellat, R., Kivelson, M. G., Walker, R. J., Russell, C. T., Baumjohann, W., Feldman, W. C., and Gosling, J. T.: Statistical characteristics of bursty bulk flow events, J. Geophys. Res., 99, 21257-21271, doi: 10.1029/94JA01263, 1994.

Balogh, A., Carr, C. M., Acuña, M. H., Dunlop, M. W., Beek, T. J., Brown, P., Fornacon, K.-H., Georgescu, E., Glassmeier, K.H., Harris, J., Musmann, G., Oddy, T., and Schwingenschuh, K.: The Cluster Magnetic Field Investigation: overview of in-flight performance and initial results, Ann. Geophys., 19, 1207-1217, doi:10.5194/angeo-19-1207-2001, 2001.

Baumjohann, W., Paschmann, G., Sckopke, N., Cattell, C. A., and Carlson, C. W.: Average ion moments in the plasma sheet boundary layer, J. Geophys. Res., 93, 11507-11520, 1988.

Baumjohann, W., Paschmann, G., and Cattell, C. A.: Average plasma properties in the central plasma sheet, J. Geophys. Res., 94, 6597-6606, 1989.

Baumjohann, W., Paschmann, G., and Luehr, H.: Characteristics of high-speed ion flows in the plasma sheet, J. Geophys. Res., 95, 3801-3809, 1990.

Blake, J. B. and Slavin, J. A.: Particle acceleration in space plasmas., Adv. Space Res., 21, 531-649, 1998.

Büchner, J. and Kuska, J.: Consequences of strong ion acceleration in current sheets and due to reconnection, Adv. Space Res., 21, 567-572, doi:10.1016/S0273-1177(97)00965-4, 1998.

Büchner, J. and Zelenyi, L. M.: Regular and chaotic charged particle motion in magnetotaillike field reversals. I - Basic theory of trapped motion, J. Geophys. Res., 94, 11821-11842, doi: 10.1029/JA094iA09p11821, 1989.

Burton, R. K., McPherron, R. L., and Russell, C. T.: An empirical relationship between interplanetary conditions and Dst, J. Geophys. Res., 80, 4204-4214, 1975.

Campbell, W. H.: Geomagnetic storms, the Dst ring-current myth and lognormal distributions, J. Atmos. Terr. Phys., 58, 1171$1187,1996$. 
Chappell, C. R., Giles, B. L., Moore, T. E., Delcourt, D. C., Craven, P. D., and Chandler, M. O.: The adequacy of the ionospheric source in supplying magnetospheric plasma, J. Atmos. SolarTerr. Phys., 62, 421-436, doi:10.1016/S1364-6826(00)00021-3, 2000.

Chaston, C. C., Hu, Y. D., and Fraser, B. J.: Non-Maxwellian particle distributions and electromagnetic ion cyclotron instabilities in the near-Earth magnetotail, Geophys. Res. Lett., 24, 2913-2916, doi:10.1029/97GL02972, 1997.

Christon, S. P., Williams, D. J., Mitchell, D. G., Frank, L. A., and Huang, C. Y.: Spectral characteristics of plasma sheet ion and electron populations during undisturbed geomagnetic conditions, J. Geophys. Res., 94, 13409-13424, 1989.

Christon, S. P., Williams, D. J., Mitchell, D. G., Huang, C. Y., and Frank, L. A.: Spectral characteristics of plasma sheet ion and electron populations during disturbed geomagnetic conditions, J. Geophys. Res., 96, 1-22, 1991.

Cully, C. M., Donovan, E. F., Yau, A. W., and Opgenoorth, H. J.: Supply of thermal ionospheric ions to the central plasma sheet, J. Geophys. Res. (Space Physics), 108, 1092-1099, doi:10.1029/ 2002JA009457, 2003.

Dandouras, I. and Barthe, A.: Cluster Active Archive:Interface Control Document for CIS, ESA, 2007.

Dandouras, I., Barthe, A., Penou, E., Rème, H., McCaffrey, S., Vallat, C., Kistler, L. M., and The Cis Team: Archival of the Cluster ion spectrometry (CIS) data in the Cluster active archive (CAA), in: Cluster and Double Star Symposium, vol. 598 of ESA Special Publication, 2006.

Delcourt, D. C.: Particle acceleration by inductive electric fields in the inner magnetosphere, J. Atmos. Solar-Terr. Phys., 64, 551559, doi:10.1016/S1364-6826(02)00012-3, 2002.

Delcourt, D. C., Pedersen, A., and Sauvaud, J. A.: Dynamics of single-particle orbits during substorm expansion phase, J. Geophys. Res., 95, 20853-20865, doi:10.1029/JA095iA12p20853, 1990.

Desai, M. I., Dayeh, M. A., and Mason, G. M.: Origin of QuietTime Suprathermal Heavy Ions Near $1 \mathrm{AU}$, in: American Institute of Physics Conference Series, edited by: Ao, X. and Burrows, G. Z. R., vol. 1183 of American Institute of Physics Conference Series, pp. 11-18, doi:10.1063/1.3266766, 2009.

Escoubet, C. P., Schmidt, R., and Goldstein, M. L.: Cluster - Science and Mission Overview, Space Sci. Rev., 79, 11-32, 1997.

Förster, M., Paschmann, G., Haaland, S. E., Quinn, J. M., Torbert, R. B., Vaith, H., and Kletzing, C. A.: High-latitude plasma convection from Cluster EDI: variances and solar wind correlations, Ann. Geophys., 25, 1691-1707, doi:10.5194/angeo-251691-2007, 2007.

Fu, S. Y., Zong, Q. G., Fritz, T. A., Pu, Z. Y., and Wilken, B.: Composition signatures in ion injections and its dependence on geomagnetic conditions, J. Geophys. Res., 107, 1299-1313, doi: 10.1029/2001JA002006, 2002.

Gold, R. E., Krimigis, S. M., Hawkins, III, S. E., Haggerty, D. K., Lohr, D. A., Fiore, E., Armstrong, T. P., Holland, G., and Lanzerotti, L. J.: Electron, Proton, and Alpha Monitor on the Advanced Composition Explorer spacecraft, Space Sci. Rev., 86, 541-562, doi:10.1023/A:1005088115759, 1998.

Gonzalez, W. D., Joselyn, J. A., Kamide, Y., Kroehl, H. W., Rostoker, G., Tsurutani, B. T., and Vasyliunas, V. M.: What is a geomagnetic storm?, J. Geophys. Res., 99, 5771-5792, doi:
10.1029/93JA02867, 1994.

Grigorenko, E. E., Hoshino, M., Hirai, M., Mukai, T., and Zelenyi, L. M.: "Geography" of ion acceleration in the magnetotail: Xline versus current sheet effects, J. Geophys. Res., 114, A03203, doi:10.1029/2008JA013811, 2009.

Horwitz, J. L.: The ionosphere as a source for magnetospheric ions, Rev. Geophys. Space Phys., 20, 929-952, 1982.

Ipavich, F. M. and Scholer, M.: Thermal and suprathermal protons and alpha particles in the earth's plasma sheet, J. Geophys. Res., 88, 150-160, 1983.

Kamide, Y., McPherron, R. L., Gonzalez, W. D., Hamilton, D. C., Hudson, H. S., Joselyn, J. A., Kahler, S. W., Lyons, L. R., Lundstedt, H., and Szuszczewicz, E.: Magnetic Storms: Current Understanding and Outstanding Questions, in: Magnetic Storms, Geophysical Monograph Series, Vol. 98, edited by: Tsurutani, B. T., Gonzalez, W. D., Kamide, Y., and Arballo, J. K., pp. 1-19, 1997.

Kamide, Y., Baumjohann, W., Daglis, I. A., Gonzalez, W. D., Grande, M., Joselyn, J. A., McPherron, R. L., Phillips, J. L., Reeves, E. G. D., Rostoker, G., Sharma, A. S., Singer, H. J., Tsurutani, B. T., and Vasyliunas, V. M.: Current understanding of magnetic storms: Storm-substorm relationships, J. Geophys. Res., 103, 17705-17728, doi:10.1029/98JA01426, 1998.

Kronberg, E. A., Daly, P., Dandouras, I., Haaland, S., and Georgescu, E.: Generation and validation of ion energy spectra based on Cluster RAPID and CIS measurements, in: The Cluster Active Archive: Studying The Earth's Space Plasma Environment, edited by: Laakso, H., Taylor, M., and Escoubet, C. P., pp. 301-306, Springer, 2010.

Lyons, L. R. and Speiser, T. W.: Evidence for current sheet acceleration in the geomagnetic tail, J. Geophys. Res., 87, 2276-2286, doi:10.1029/JA087iA04p02276, 1982.

Mailyan, B., Munteanu, C., and Haaland, S.: What is the best method to calculate the solar wind propagation delay?, Ann. Geophys., 26, 2383-2394, doi:10.5194/angeo-26-2383-2008, 2008.

Meng, C.-I., Lui, A. T. Y., Krimigis, S. M., Ismail, S., and Williams, D. J.: Spatial distribution of energetic particles in the distant magnetotail, J. Geophys. Res., 86, 5682-5700, doi: 10.1029/JA086iA07p05682, 1981.

Mitchell, D. G., C:Son Brandt, P., Roelof, E. C., Hamilton, D. C., Retterer, K. C., and Mende, S.: Global imaging of $\mathrm{O}^{+}$from IMAGE/HENA, Space Sci. Rev., 109, 63-75, doi:10.1023/B: SPAC.0000007513.55076.00, 2003.

Moebius, E., Scholer, M., Klecker, B., Hovestadt, D., and Gloeckler, G.: Acceleration of ions of ionospheric origin in the plasma sheet during substorm activity, pp. 231-234, Johns Hopkins University Press, 1987.

Nosé, M., Lui, A. T. Y., Ohtani, S., Mauk, B. H., McEntire, R. W., Williams, D. J., Mukai, T., and Yumoto, K.: Acceleration of oxygen ions of ionospheric origin in the near-Earth magnetotail during substorms, J. Geophys. Res., 105, 7669-7678, doi: 10.1029/1999JA000318, 2000.

Nosé, M., Takahashi, K., Ohtani, S., Christon, S. P., and McEntire, R. W.: Dynamics of Ions of Ionospheric Origin During Magnetic Storms: Their Acceleration Mechanism and Transport Path to Ring Current, in: The Inner Magnetosphere: Physics and Modeling, edited by: T. I. Pulkkinen, N. A. Tsyganenko, and R. H. W. Friedel, vol. 155 of Washington D.C. American Geo- 
physical Union Geophysical Monograph Series, pp. 61-70, AGU Books Board, Washington, D.C. USA, 2005.

Nosé, M., Taguchi, S., Christon, S. P., Collier, M. R., Moore, T. E., Carlson, C. W., and McFadden, J. P.: Response of ions of ionospheric origin to storm time substorms: Coordinated observations over the ionosphere and in the plasma sheet, J. Geophys. Res. (Space Physics), 114, A05207, doi:10.1029/2009JA014048, 2009.

O'Brien, T. P. and McPherron, R. L.: An empirical phase space analysis of ring current dynamics: Solar wind control of injection and decay, J. Geophys. Res., 105, 7707-7720, doi:10.1029/ 1998JA000437, 2000.

Ono, Y., Nosé, M., Christon, S. P., and Lui, A. T. Y.: The role of magnetic field fluctuations in nonadiabatic acceleration of ions during dipolarization, J. Geophys. Res., 114, 5209-5220, doi: 10.1029/2008JA013918, 2009.

Pulkkinen, T. I., Baker, D. N., Cogger, L. L., Frank, L. A., Sigwarth, J. B., Kokubun, S., Mukai, T., Singer, H. J., Slavin, J. A., and Zelenyi, L.: Spatial extent and dynamics of a thin current sheet during the substorm growth phase on December 10, 1996, J. Geophys. Res., 104, 28475-28490, doi:10.1029/1999JA900240, 1999.

Rème, H., Aoustin, C., Bosqued, J. M., Dandouras, I., Lavraud, B., Sauvaud, J. A., Barthe, A., Bouyssou, J., Camus, Th., CoeurJoly, O., Cros, A., Cuvilo, J., Ducay, F., Garbarowitz, Y., Medale, J. L., Penou, E., Perrier, H., Romefort, D., Rouzaud, J., Vallat, C., Alcaydé, D., Jacquey, C., Mazelle, C., d’Uston, C., Möbius, E., Kistler, L. M., Crocker, K., Granoff, M., Mouikis, C., Popecki, M., Vosbury, M., Klecker, B., Hovestadt, D., Kucharek, H., Kuenneth, E., Paschmann, G., Scholer, M., Sckopke, N., Seidenschwang, E., Carlson, C. W., Curtis, D. W., Ingraham, C., Lin, R. P., McFadden, J. P., Parks, G. K., Phan, T., Formisano, V., Amata, E., Bavassano-Cattaneo, M. B., Baldetti, P., Bruno, R., Chionchio, G., Di Lellis, A., Marcucci, M. F., Pallocchia, G., Korth, A., Daly, P. W., Graeve, B., Rosenbauer, H., Vasyliunas, V., McCarthy, M., Wilber, M., Eliasson, L., Lundin, R., Olsen, S., Shelley, E. G., Fuselier, S., Ghielmetti, A. G., Lennartsson, W., Escoubet, C. P., Balsiger, H., Friedel, R., Cao, J.-B., Kovrazhkin, R. A., Papamastorakis, I., Pellat, R., Scudder, J., and Sonnerup, B.: First multispacecraft ion measurements in and near the Earth's magnetosphere with the identical Cluster ion spectrometry (CIS) experiment, Ann. Geophys., 19, 1303-1354, doi:10.5194/angeo19-1303-2001, 2001.

Rostoker, G., Akasofu, S., Foster, J., Greenwald, R. A., Lui, A. T. Y., Kamide, Y., Kawasaki, K., McPherron, R. L., and Russell, C. T.: Magnetospheric substorms - Definition and signatures, J. Geophys. Res., 85, 1663-1668, doi:10.1029/ JA085iA04p01663, 1980.

Ruan, P., Fu, S. Y., Zong, Q., Pu, Z. Y., Cao, X., Liu, W. L., Zhou, X. Z., and Daly, P. W.: Ion composition variations in the plasma sheet observed by Cluster/RAPID, Geophys. Res. Lett., 32, 1105-1109, doi:10.1029/2004GL021266, 2005.

Russell, C. T. and McPherron, R. L.: Semiannual variation of geomagnetic activity., J. Geophys. Res., 78, 92-108, doi:10.1029/ JA078i001p00092, 1973.

Sanchez, E. R., Mauk, B. H., and Meng, C.: Adiabatic vs. nonadiabatic particle distributions during convection surges, Geophys. Res. Lett., 20, 177-180, doi:10.1029/93GL00237, 1993.

Sanny, J., McPherron, R. L., Russell, C. T., Baker, D. N., Pulkkinen,
T. I., and Nishida, A.: Growth-phase thinning of the near-Earth current sheet during the CDAW 6 substorm, J. Geophys. Res., 99, 5805-5816, doi:10.1029/93JA03235, 1994.

Sarafopoulos, D. V.: A physical mechanism producing suprathermal populations and initiating substorms in the Earth's magnetotail, Ann. Geophys., 26, 1617-1639, doi:10.5194/angeo-261617-2008, 2008.

Sarafopoulos, D. V., Sidiropoulos, N. F., Sarris, E. T., Lutsenko, V., and Kudela, K.: The dawn-dusk plasma sheet asymmetry of energetic particles: An interball perspective, J. Geophys. Res., 106, 13053-13066, doi:10.1029/2000JA900157, 2001.

Scholer, M., Hovestadt, D., Ipavich, F. M., and Gloeckler, G.: Upstream energetic ions and electrons - Bow shock-associated or magnetospheric origin, J. Geophys. Res., 86, 9040-9046, doi: 10.1029/JA086iA11p09040, 1981.

Schwartz, S. J.: Shock and Discontinuity Normals, Mach Numbers, and Related Parameters, in: Analysis Methods for MultiSpacecraft Data, edited by: Paschmann, G. and Daly, P. W., ISSI SR-001, p. 249, ESA Publications Division, 1998.

Sergeev, V. A., Apatenkov, S. V., Angelopoulos, V., McFadden, J. P., Larson, D., Bonnell, J. W., Kuznetsova, M., Partamies, N., and Honary, F.: Simultaneous THEMIS observations in the near-tail portion of the inner and outer plasma sheet flux tubes at substorm onset, J. Geophys. Res., 113, A00C02, doi: 10.1029/2008JA013527, 2008.

Speiser, T. W.: Particle Trajectories in Model Current Sheets, 1, Analytical Solutions, J. Geophys. Res., 70, 4219-4226, doi:10. 1029/JZ070i017p04219, 1965.

Speiser, T. W.: Current sheet particle acceleration - Theory and observations for the geomagnetic tail, Adv. Space Res., 4, 439448, doi:10.1016/0273-1177(84)90344-2, 1984.

Speiser, T. W. and Lyons, L. R.: Comparison of an analytical approximation for particle motion in a current sheet with precise numerical calculations, J. Geophys. Res., 89, 147-158, doi: 10.1029/JA089iA01p00147, 1984.

Thorne, R. M. and Summers, D.: Enhancement of wave growth for warm plasmas with a high-energy tail distribution, J. Geophys. Res., 96, 217-223, doi:10.1029/90JA01629, 1991.

Torkar, K., Riedler, W., Escoubet, C. P., Fehringer, M., Schmidt, R., Grard, R. J. L., Arends, H., Rüdenauer, F., Steiger, W., Narheim, B. T., Svenes, K., Torbert, R., André, M., Fazakerley, A., Goldstein, R., Olsen, R. C., Pedersen, A., Whipple, E., and Zhao, H.: Active spacecraft potential control for Cluster implementation and first results, Ann. Geophys., 19, 1289-1302, doi:10.5194/angeo-19-1289-2001, 2001.

Turner, N. E., Baker, D. N., Pulkkinen, T. I., and McPherron, R. L.: Evaluation of the tail current contribution to Dst, J. Geophys. Res., 105, 5431-5440, doi:10.1029/1999JA000248, 2000.

Vasyliunas, V. M.: A Survey of Low-Energy Electrons in the Evening Sector of the Magnetosphere with OGO 1 and OGO 3, J. Geophys. Res., 73, 2839-2852, doi:10.1029/JA073i009p02839, 1968.

Venables, W. N. and Ripley, B. D.: Modern Applied Statistics with S-PLUS, Springer, 3rd edn., 1999.

Weimer, D. R. and King, J. H.: Improved calculations of interplanetary magnetic field phase front angles and propagation time delays, J. Geophys. Res., 113, A01105, doi:10.1029/ 2007JA012452, 2008.

Weimer, D. R., Ober, D. M., Maynard, N. C., Collier, M. R., McCo- 
mas, D. J., Ness, N. F., Smith, C. W., and Watermann, J.: Predicting interplanetary magnetic field (IMF) propagation delay times using the minimum variance technique, J. Geophys. Res., 108, 1026, doi:10.1029/2002JA009405, 2003.

West Jr., H. I. and Buck, R. M.: A study of electron spectra in the inner belt, J. Geophys. Res., 81, 4696-4700, 1976.

Wilken, B., Daly, P. W., Mall, U., Aarsnes, K., Baker, D. N., Belian, R. D., Blake, J. B., Borg, H., Bchner, J., Carter, M., Fennell, J. F., Friedel, R., Fritz, T. A., Gliem, F., Grande, M., Kecskemety, K., Kettmann, G., Korth, A., Livi, S., McKenna-Lawlor, S., Mursula, K., Nikutowski, B., Perry, C. H., Pu, Z. Y., Roeder, J., Reeves, G. D., Sarris, E. T., Sandahl, I., Sraas, F., Woch, J., and Zong, Q.-G.: First results from the RAPID imaging energetic particle spectrometer on board Cluster, Ann. Geophys., 19, 1355-1366, doi:10.5194/angeo-19-1355-2001, 2001.

Williams, D. J., Fritz, T. A., and Konradi, A.: Observations of Proton Spectra $(1.0 \leq \mathrm{Ep} \leq 300 \mathrm{kev})$ and Fluxes at the Plasmapause, J. Geophys. Res., 78, 4751-4755, doi:10.1029/ JA078i022p04751, 1973.
Wygant, J. R., Cattell, C. A., Lysak, R., Song, Y., Dombeck, J., McFadden, J., Mozer, F. S., Carlson, C. W., Parks, G., Lucek, E. A., Balogh, A., Andre, M., Reme, H., Hesse, M., and Mouikis, C.: Cluster observations of an intense normal component of the electric field at a thin reconnecting current sheet in the tail and its role in the shock-like acceleration of the ion fluid into the separatrix region, J. Geophys. Res., 110, A09206, doi:10.1029/ 2004JA010708, 2005.

Yau, A. W., Lenchyshyn, L., Shelley, E. G., and Peterson, W. K.: Energetic auroral and polar ion outflow at DE 1 altitudes Magnitude, composition, magnetic activity dependence, and longterm variations, J. Geophys. Res., 90, 8417-8432, doi:10.1029/ JA090iA09p08417, 1985.

Young, D. T., Balsiger, H., and Geiss, J.: Correlations of magnetospheric ion composition with geomagnetic and solar activity, J. Geophys. Res., 87, 9077-9096, doi:10.1029/JA087iA11p09077, 1982. 